\title{
AUTOMATIC WHEEL-LOADER IN ASPHALT PLANT
}

\author{
Tomohiro Gocholl, Narimasa Yamabe1), Takehisa Hamaguchi1) \\ Shin-ichi Hitomi2), Toyoichi Ono2), Hiroshi Oshima2), Masaki Mori2) \\ Masao Fukuda ${ }^{3}$ \\ 1) Nippon Hodo Co., Ltd. 6-70 Mihashi, Omiya-shi, Saitama 331 Japan \\ 2) Komatsu Ltd. 1200 Manda, Hiratsuka-shi, Kanagawa 254 Japan \\ 3) Komatsu MEC Co. 1-9 Minamidai, Kawagoe-shi, Saitama 350 Japan
}

\section{ABSTRACT}

Komatsu, Ltd. and Nippon Hodo Co., Ltd. have jointly developed an unmanned automatic operation system for wheel loaders for the execution of routine works in asphalt plants (scooping, transportation and loading). This system was introduced on a wheel loader in the Shimonoseki Plant of Nippon Hodo Co., Ltd. and is being operated for demonstration purposes. This automatic wheel loader is equipped with a high-performance microcomputer and various sensors and actuators and is able to perform various works automatically according to work instructions from a controller separately located at the site.

\section{INTRODUCTION}

Recently, the construction industry has been experiencing serious problems, such as young workers leaving the manufacturing industry, as well as a chronic labor shortage and sluggish productivity due to a poor working environment.

This is also the case for operators of wheel loaders in asphalt plants.

Figure 1 shows a typical asphalt plant. The plant consists of stockyard, hopper, dryer, and mixing tower. Material is periodically brought to the stock-yard by dump truck.

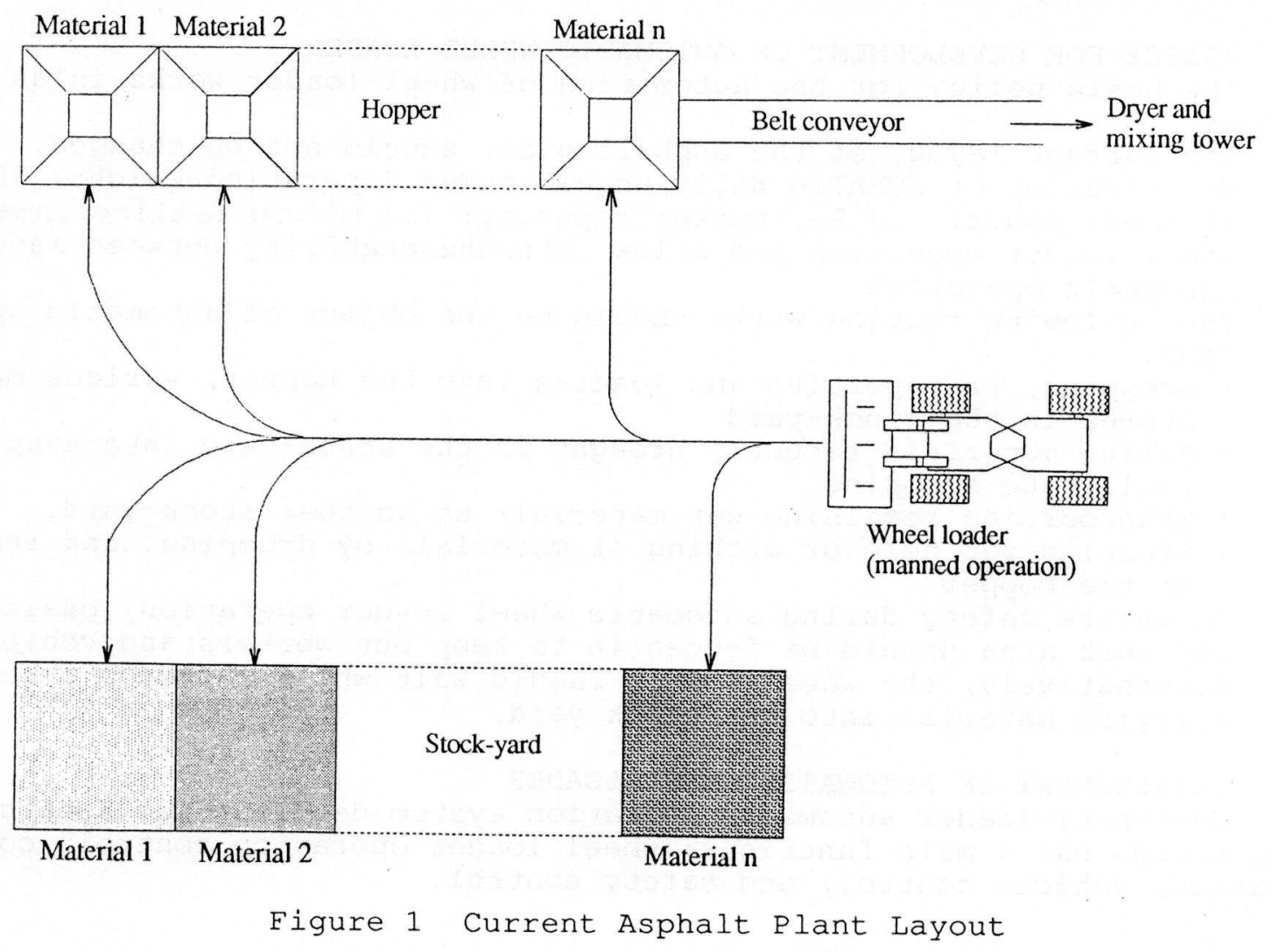


Wheel loaders are used mainly to supply material such as crushed rock and sand to the hopper from the stock-yard. Operating a wheel loader is dull, monotonous and difficult work which continues for long periods of time in a severe environment where operators are exposed to noise, vibration and dust. This, combined with the labor shortage, makes it difficult to secure operators. This fact, as well as the productivity problem, has necessitated the introduction of automated wheel loaders.

However, several problems remain unsolved concerning the automation of wheel loaders.

(1) Large size of stock-yard makes it difficult to locate required materials easily.

(2) Dump trucks carrying material into the stock-yard are also operated in the wheel loader working range.

(3) Wheel loaders for asphalt plants are required to execute a diversity of

works in addition to supplying material. These include scooping,

transportation and loading of materials.

Under such circumstances, we carried out a cost analysis on the unmanned wheel loader, set a target for approximately $75 \%$ of overall work to be executed without an operator by automating the routine work, and

determined the following specifications and operating conditions.

(1) Capacity of unmanned wheel loader: 70 ton per hour

(2) The wheel loader work area should be enclosed by a safety fence to secure safety of workers during unmanned operation.

(3) A period of 4 hours in the morning should be established for unmanned wheel loader operation during which dump trucks are not permitted to transport material into the stock-yard, thus ensuring that they are kept out of the working area

(4) Material should be carried into the stock-yard only in the afternoon by operator-driven wheel loader. If unmanned operation is required, the wheel loader must wait on a side track while dump trucks enter the working area.

This report describes the configuration, control method, safety measures, and operating method of the automatic wheel loader system.

2. POLICY FOR DEVELOPMENT OF AUTOMATIC WHEEL LOADER

The basic policy for the automation of wheel loader works is as follows.

(1) The current layout of the asphalt plant should not be changed.

(2) Modification of KOMATSU WA150 wheel loader (operating weight: $7840 \mathrm{~kg}$, flywheel power: $110 \mathrm{PS}$, bucket capacity: $1.7 \mathrm{~m}^{3}$ ) to realize unmanned wheel loader operation and allow interchangeability between manual and automatic operation.

(3). The following routine works should be the object of automatic operation.

- Scooping, transporting and loading into the hopper, various materials stored in the stock-yard

- Piling materials recently brought to the stock-yard into heaps to facilitate scooping

- Transporting remaining wet materials to another stock-yard.

- Breaking rat hole or arching of materials by dropping sand remaining in the hopper

(4) To ensure safety during automatic wheel loader operation, basically, the work area should be fenced in to keep out workers and vehicles. Alternatively, the wheel loader should wait while the dump trucks are carrying material into the stock-yard.

3. DEVELOPMENT OF AUTOMATIC WHEEL LOADER

The wheel-loader automatic operation system developed by Komatsu and Nippon Hodo has 4 main functions: wheel loader operation control, communication, vehicle control, and safety control. 
3.1 Wheel Loader Operation Control

Wheel loader operation is controlled by an operation controller separately located at the site. Figure 2 shows the configuration of the related peripheral equipment. Controller functions are as follows.

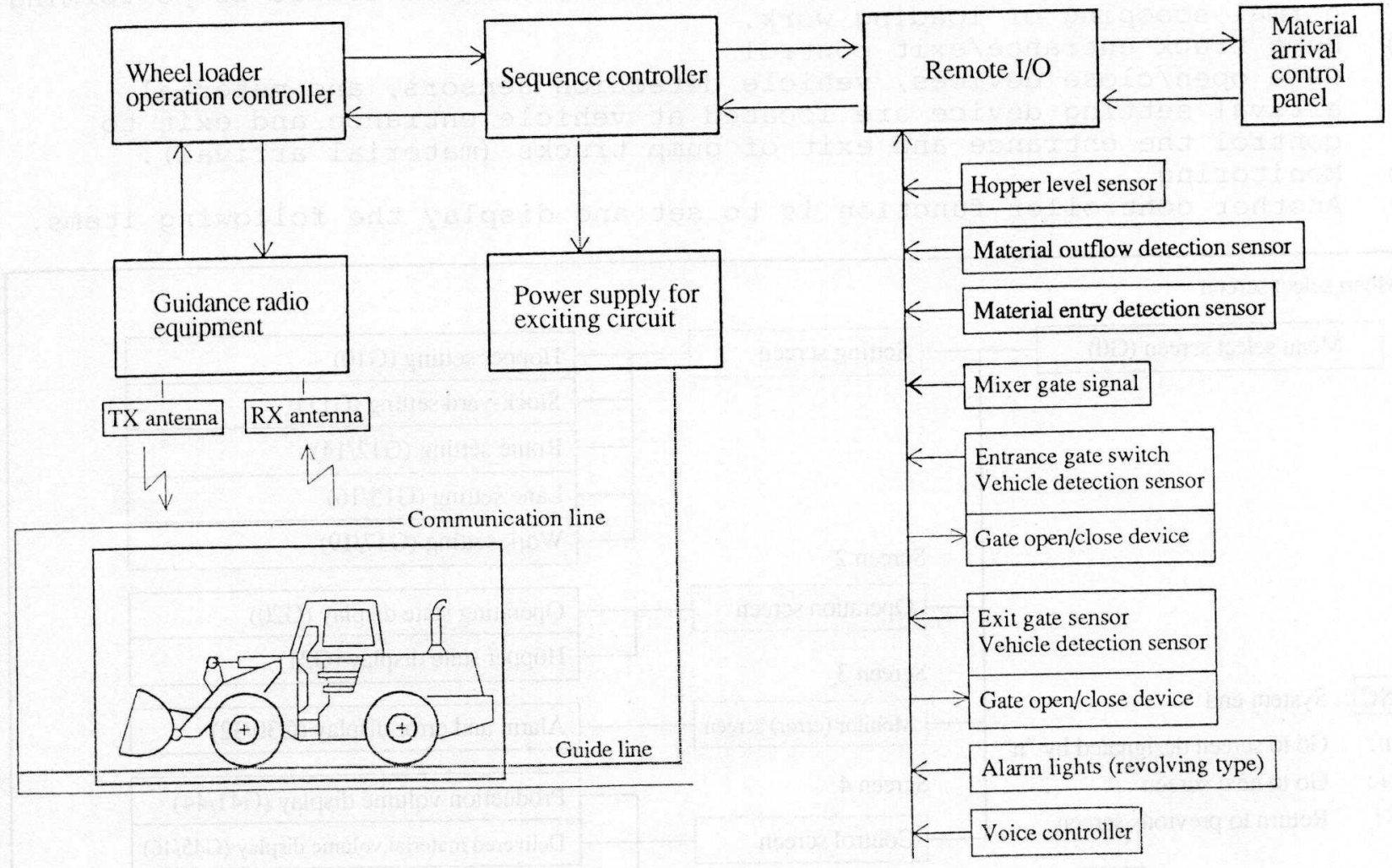

Figure 2 Wheel Loader Operation Control System

(1) Wheel loader guidance

As shown in Figure 3, guide line and positioning line are laid underground. The path to be taken by the vehicle is determined by changing over the exciting circuit using the sequence controller (see references (1) and (2)).

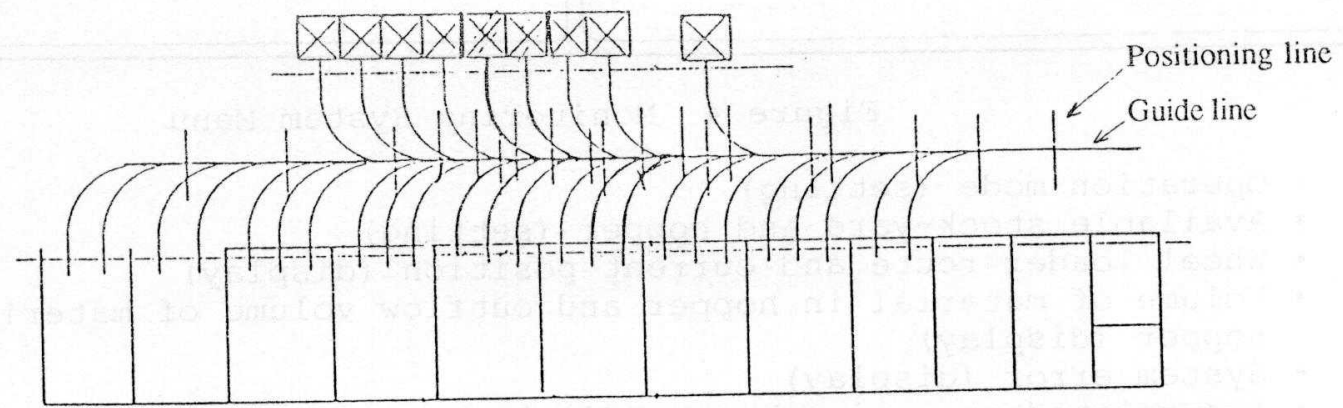

Figure 3 Layout of Guide and Positioning Lines

(2) Work sequence control

Two work modes are available: SCHEDULE mode which operates the wheel loader according to the efficient schedule programmed in the operation controller and HEIGHT LEVEL SENSOR mode which continuously monitors the decrease in each material in the hopper using the height level sensor and operates the wheel loader to load the material with the highest reduction rate on a priority basis. In addition, this controller 
selects special works and issues its command to the wheel loader. Such works include piling materials when new material is delivered, breaking rat hole or arching of material when outflow of material from the hopper stops, or relocating wet materials when the number of excavations reaches the limit value, even when the wheel loader is performing normal scooping or loading work.

(3) Dump truck entrance/exit control

Gate open/close devices, vehicle detection sensors, and material arrival setting device are located at vehicle entrance and exit to control the entrance and exit of dump trucks (material arrival).

(4) Monitoring

Another controller function is to set and display the following items.

\begin{tabular}{|c|c|c|}
\hline \multicolumn{3}{|l|}{ Menu select screen } \\
\hline Menu select screen (G0) & Setting screen & Hopper setting (G10) \\
\hline \multirow{6}{*}{. } & \multirow{4}{*}{ Screen 2} & Stock-yard setting (G11) \\
\hline & & Route setting (G12/14) \\
\hline & & Lane setting (G15/16) \\
\hline & & Work setting (G17/19) \\
\hline & Operation screen & Operating state display (G20) \\
\hline & & Hopper state display (G21) \\
\hline ESC: System end & Monitor (error) screen & \multirow[t]{2}{*}{ Alarm and error display (G30/32) } \\
\hline \multirow{3}{*}{$\begin{array}{ll}\text { Gn: } & \text { Go to screen designated by "n" } \\
\text { G+: } & \text { Go to next screen } \\
G-: & \text { Return to previous screen }\end{array}$} & & \\
\hline & Screen 4 & Production volume display (G41/44) \\
\hline & Control screen & Delivered material volume display (G45/46) \\
\hline \multicolumn{2}{|l|}{ Menu select $(\mathrm{Gn} / \mathrm{G}+/ \mathrm{G}-/ \mathrm{ESC})$} & Alarm and error conditions (G47/49) \\
\hline Screen No. & & HELP screen (G40) \\
\hline Message & & (G0) \\
\hline
\end{tabular}

Figure 4 Monitoring System Menu

- Operation mode (setting)

- Available stock-yard and hopper (setting)

- Wheel loader route and current position (display)

- Volume of material in hopper and outflow volume of material from hopper (display)

- System error (display)

- Accumulated operating hours (display)

3.2 Communication Method

(1) Communication method

Dual direction communication by induction wireless telegraph is executed between the operation controller at the site and the built-in controller mounted on the wheel loader through the communication line laid underground beneath the travel route. 
- Type of material

- Type of work

- Excavation pattern

- Error occurrence

- Current position

- Start position

- Commands to vehicle

- Receipt confirmation code

- Vehicle condition

\subsection{Vehicle Control}

Figure 5 shows the configuration of the system mounted on the automatic wheel loader.

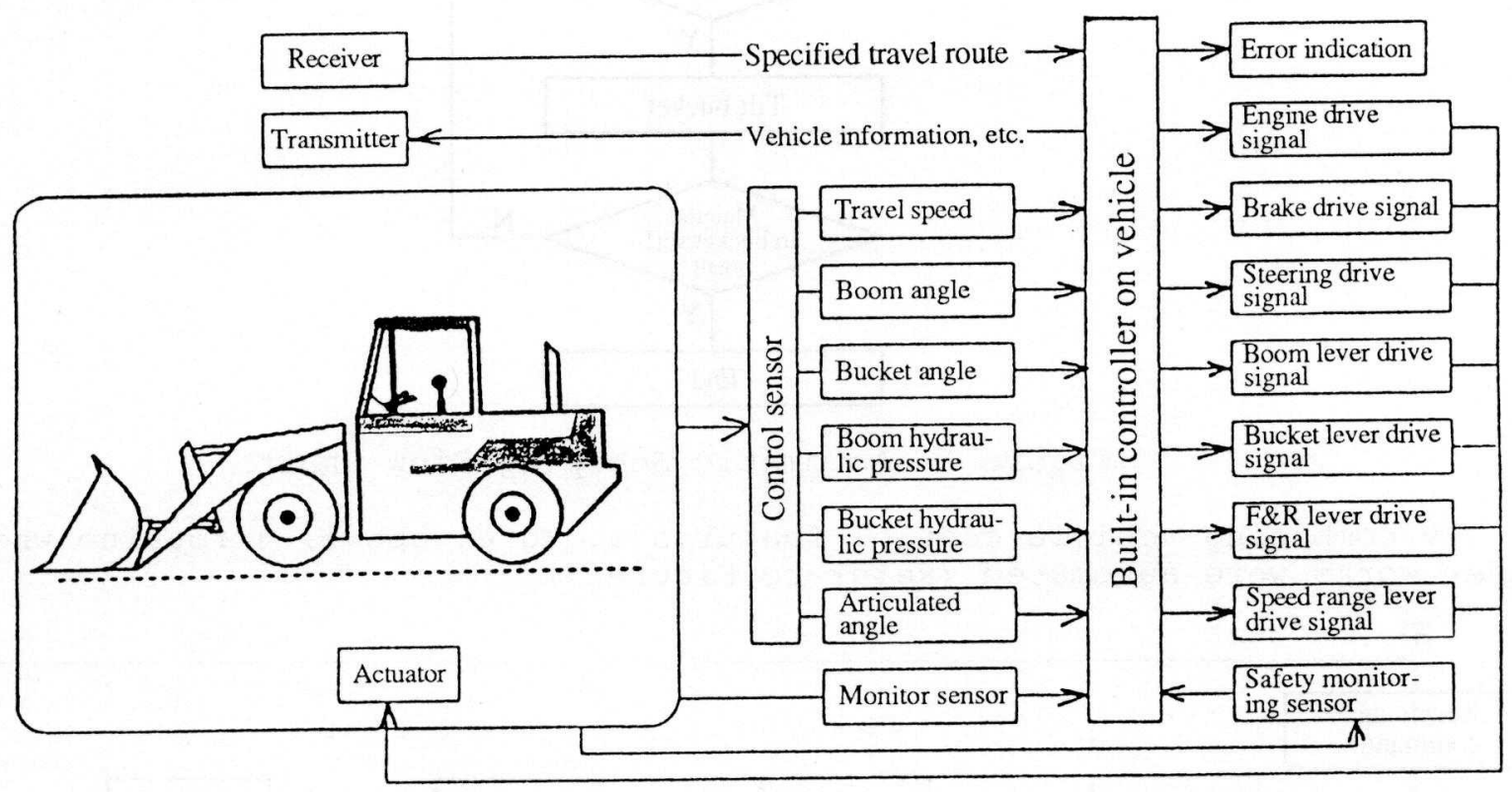

Figure 5 Built-in System Mounted on Automatic Wheel Loader

(1) Vehicle operation control

a. Engine control

Detect travel speed and engine speed and control engine output power according to deviation from target.

b. Brake control

Detect brake hydraulic pressure in the brake circuit and control it according to braking pattern (loaded, empty, emergency stop).

c. Transmission control

To change over forward/reverse direction or change gear ratio, the transmission valve is directly driven by the proportional solenoid valve.

d. Steering control

Calculate deviation from the specified course using the pickup coil data, set target steering angle, and control articulated angle according to the difference between the target and actuallymeasured articulated angle by the sensor mounted on the wheel loader.

e. Work equipment (boom and bucket) control

Detect boom and bucket angles and position them by operating the work equipment valves according to the deviation from their target angles. During scooping work, calculate scoop load from the measured data by the hydraulic pressure sensor on the work equipment and automatically control the work equipment valves according to the load. Figure 6 shows the automatic scooping flow chart. 


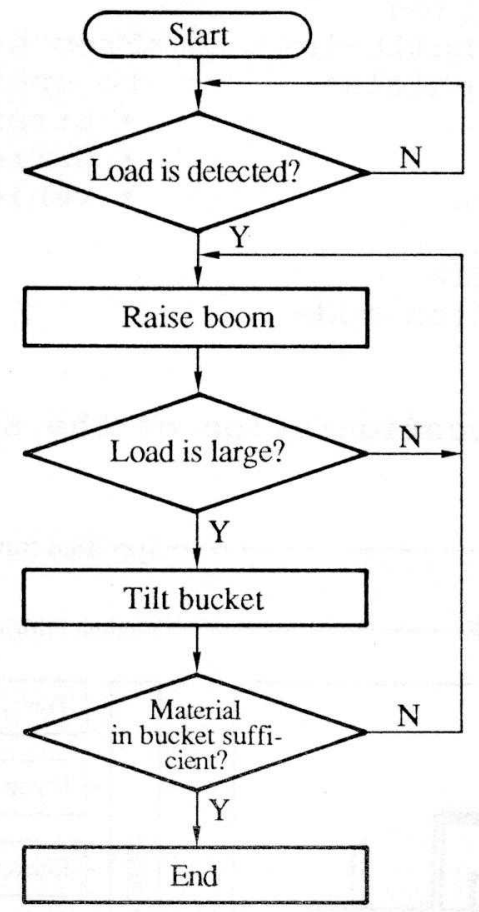

Figure 6 Automatic Scooping Flow Chart

By combining vehicle control features a. to e. above, 4 routine wheelloader works were automated (Refer to Eigure 7).

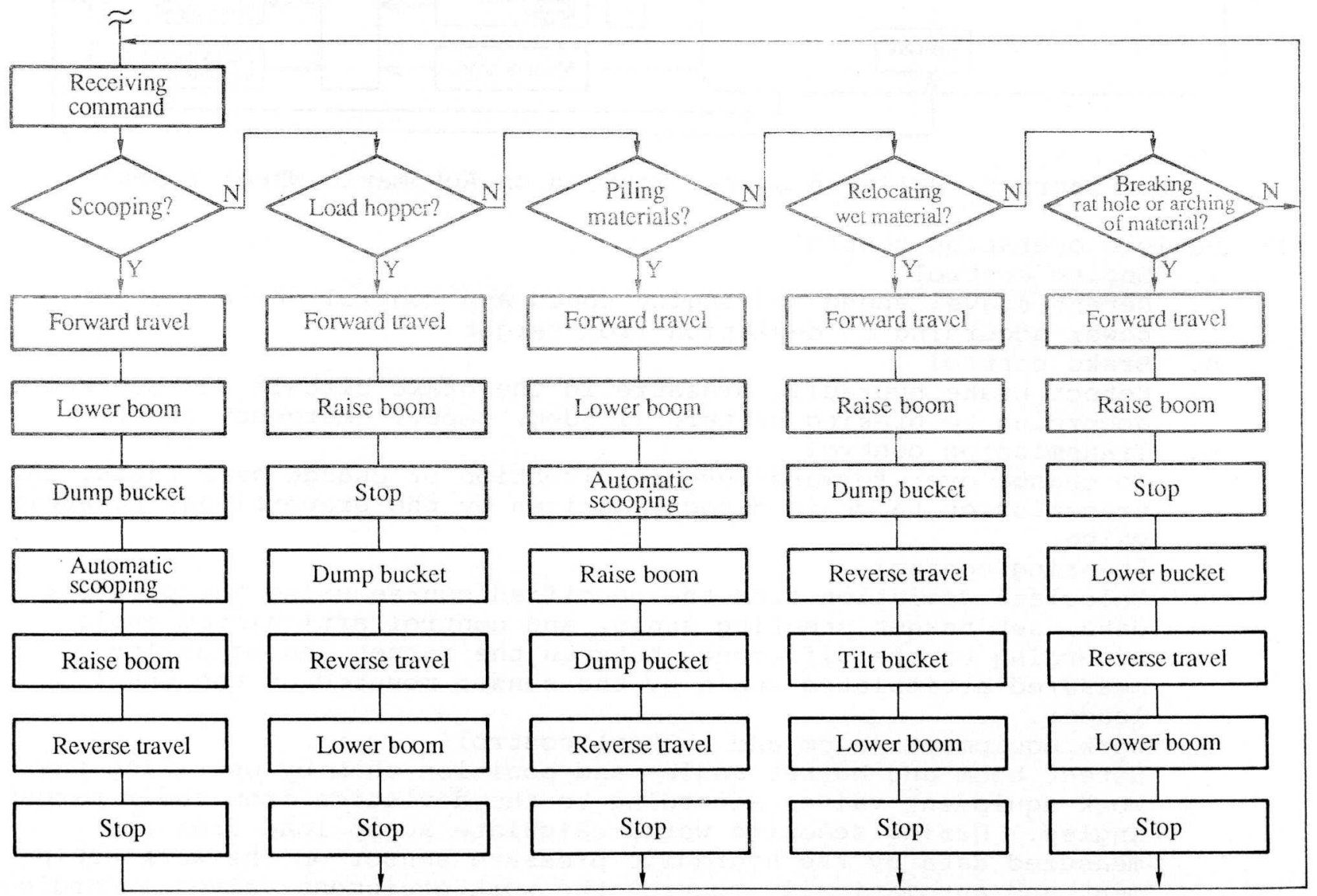

Figure 7 Automation of Wheel Loader Works 
3.4 Safety measures

(1) Safety measures in asphalt plant (Refer to Figure 8)

a. Safety fence and door

The automatic operation system is fenced off from the outside to prevent workers from entering the plant during operation. In addition, while operation is stopped, entrance is limited to the safety door. If the safety door is opened during automatic operation, the wheel loader is emergency-stopped.

b. Entrance and exit gates for dump trucks

Exclusive gates are installed for carrying materials into the stock-yard, and entrance of dump trucks is allowed only when wheel loader has stopped.

c. Entrance detection sensor

When the sensor beam is cut, it is judged that workers or dump trucks have entered the working area, and the wheel loader is emergency-stopped.

d. Operation indication lamps Indicate operation condition (waiting, traveling, abnormal) of the automatic operation system.

e. Monitor camera

Enables plant operators in the office to monitor the operating state of both the wheel loader and the site to secure the safety of the entire system.

f. Emergency stop switch

Emergency stop switches are equipped inside and outside the plant as well as in the office. Thus, in the event of an emergency, the wheel loader can be stopped immediately.

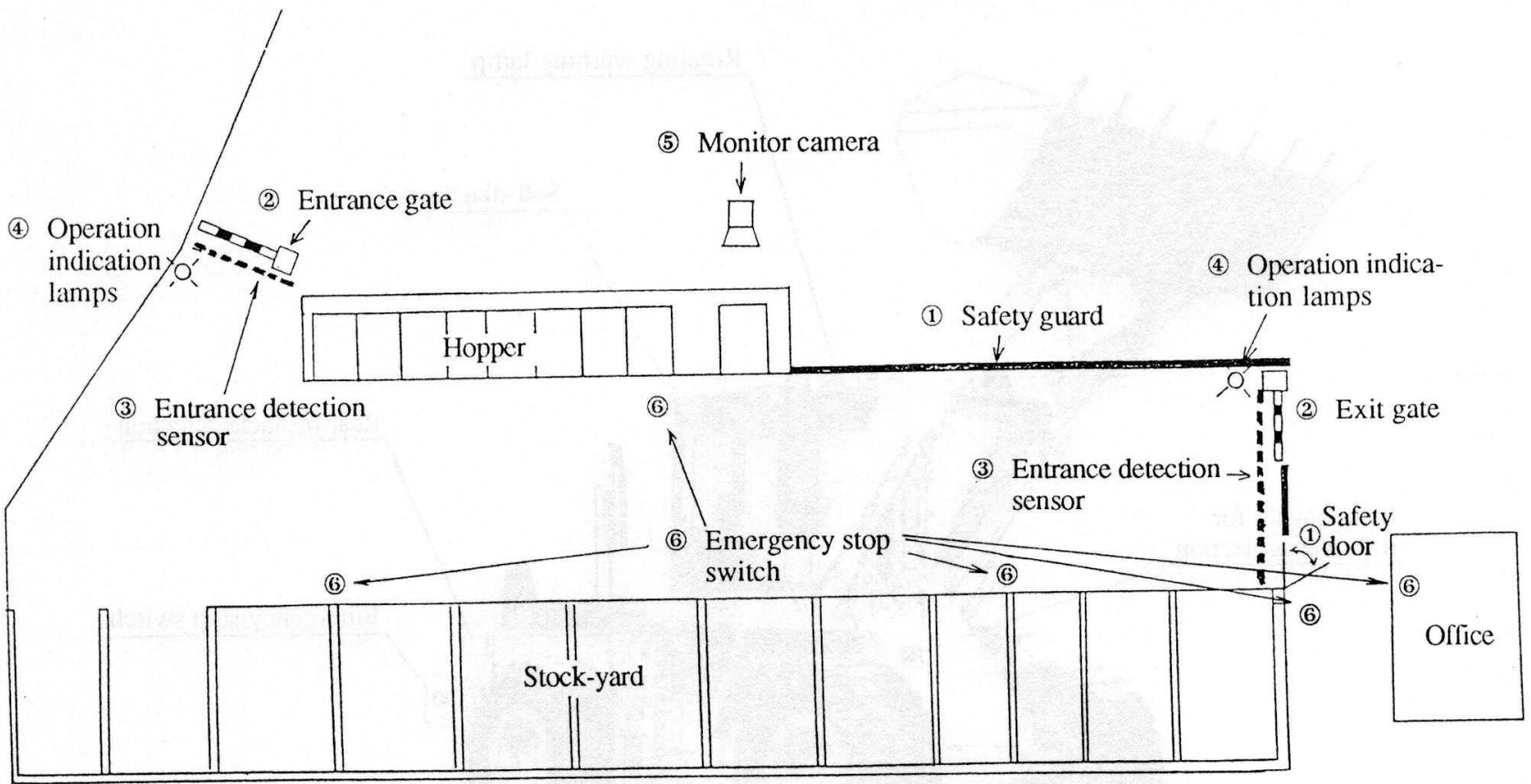

Figure 8 Safety Measures in Asphalt Plant 
(2) Vehicle safety measures (Refer to Figure 9)

a. Prevention of roll-over

Detects pitching and rolling angles of the wheel loader and applies emergency-stop when any of the angles reaches the roll-over danger level.

b. Course-out detection

If the signal level of the pickup coil for wheel load guidance drops below the set value, it is judged that the wheel loader has deviated from the specified course, and the wheel loader is stopped immediately.

c. Rear obstacle detection

The ultrasonic sensor mounted at the rear of the wheel loader detects any object within the set distance behind the loader as an obstacle, and immediately stops the wheel loader.

d. Emergency stop switch

Cuts fuel supply to the engine to immediately stop the engine.

e. Revolving warning lamp

Indicates the current state of the automatic operation system.

- Blue: In waiting state during automatic travel

- Yellow: In automatic travel

- Red: In emergency stop condition

f. Self-diagnosis

- Sensor signal level check

- Actuator supply current check

- Travel speed check

- Work sequence speed check

- Travel distance check

- Actuator operating time check

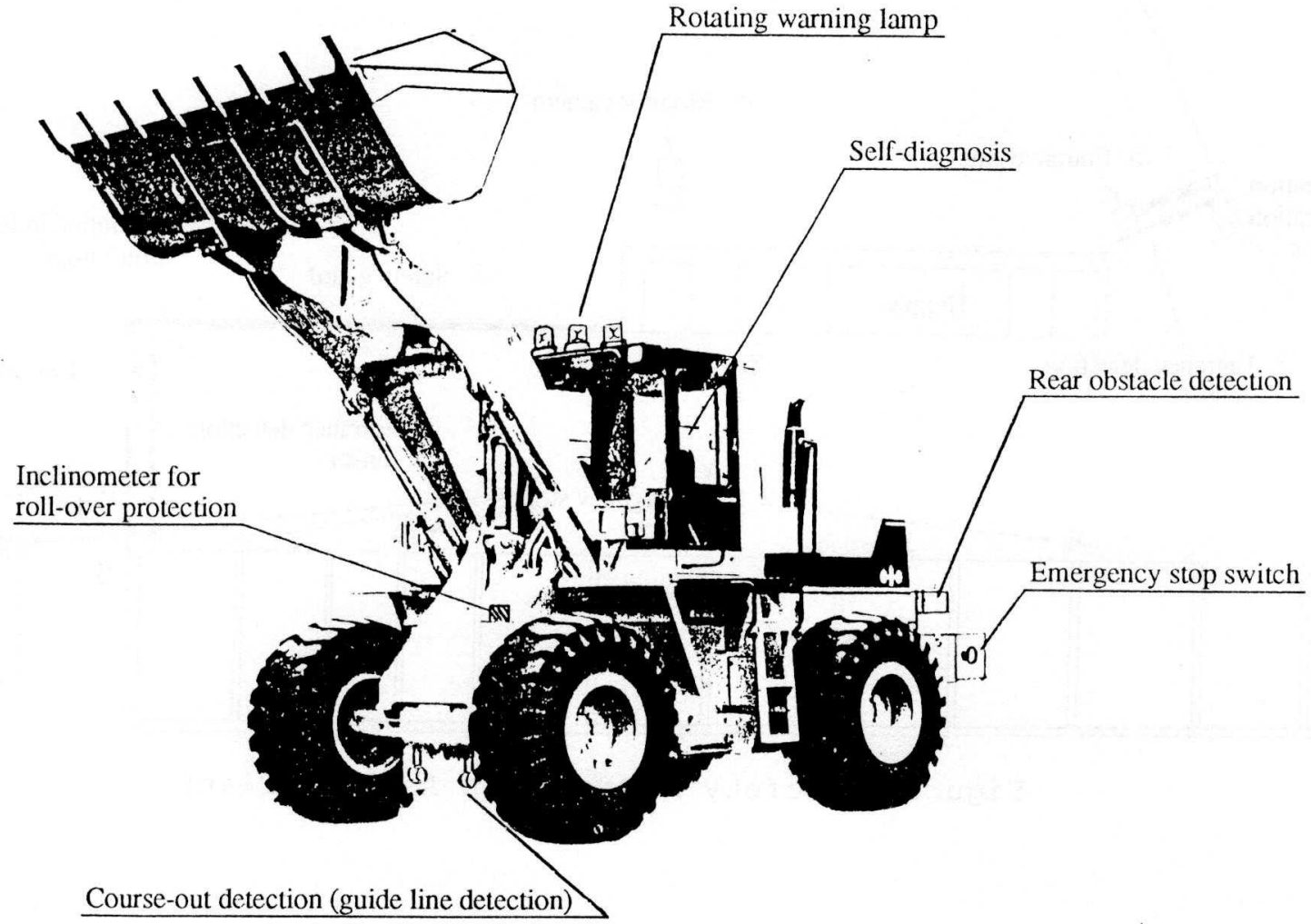

Figure 9 Safety Devices on the Automatic Wheel Loader 
4. TEST RESULTS

Table 1 shows the test results, while Figures 10 , 11 and
workes during the test. Table 1 Test Results

\begin{tabular}{|c|c|c|c|}
\hline \multicolumn{2}{|r|}{ Item } & \multirow{2}{*}{\begin{tabular}{|l|}
\multicolumn{1}{|c|}{ Target } \\
$75 \%$ of (1) Material supply \\
(2) Relocating wet materials \\
(3) Piling materials \\
(4) Breaking rat hole or arching \\
of material \\
\end{tabular}} & Result \\
\hline $\begin{array}{l}\text { Automatic } \\
\text { operation }\end{array}$ & Automatization percentage & & $\begin{array}{l}75 \% \text { of (1) Material supply } \\
\text { (2) Relocating wet materials } \\
\text { (3) Piling materials } \\
\text { (4) Breaking rat hole or arching } \\
\text { of material }\end{array}$ \\
\hline \multirow[t]{3}{*}{ Material supply } & Supply capacity & $70 \mathrm{t} / \mathrm{h}$ & $70 \mathrm{t} / \mathrm{h}$ or more \\
\hline & Bucket max. filling ratio & $88 \%$ or more & Average $90 \%$ \\
\hline & Continuous operation time & 4 hours or more & 4 hours \\
\hline
\end{tabular}

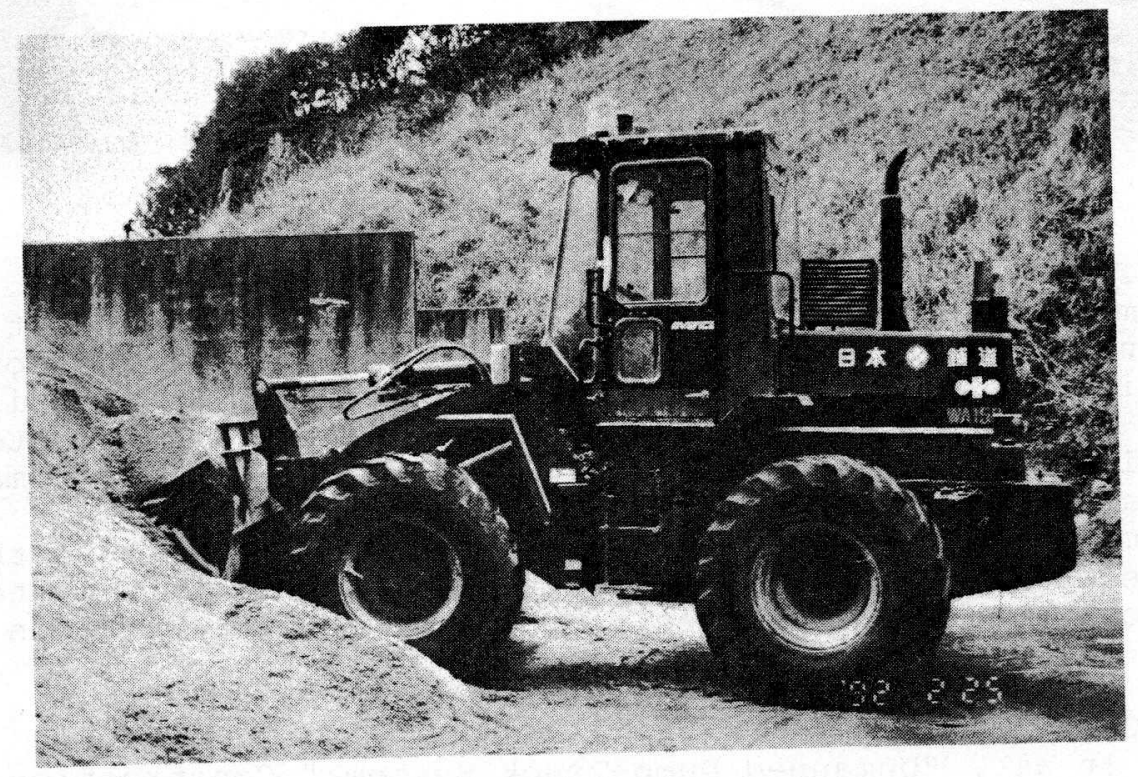

\section{Eigure 10 Test Scene}

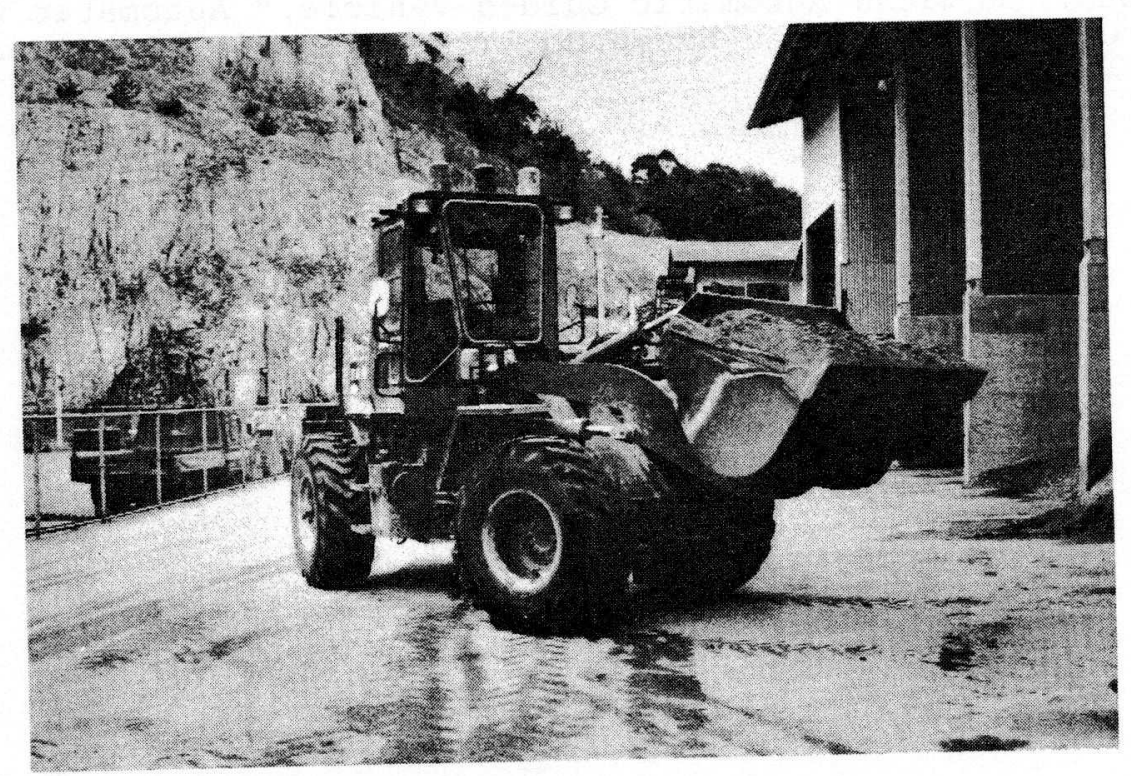

Figure 11 Test Scene 


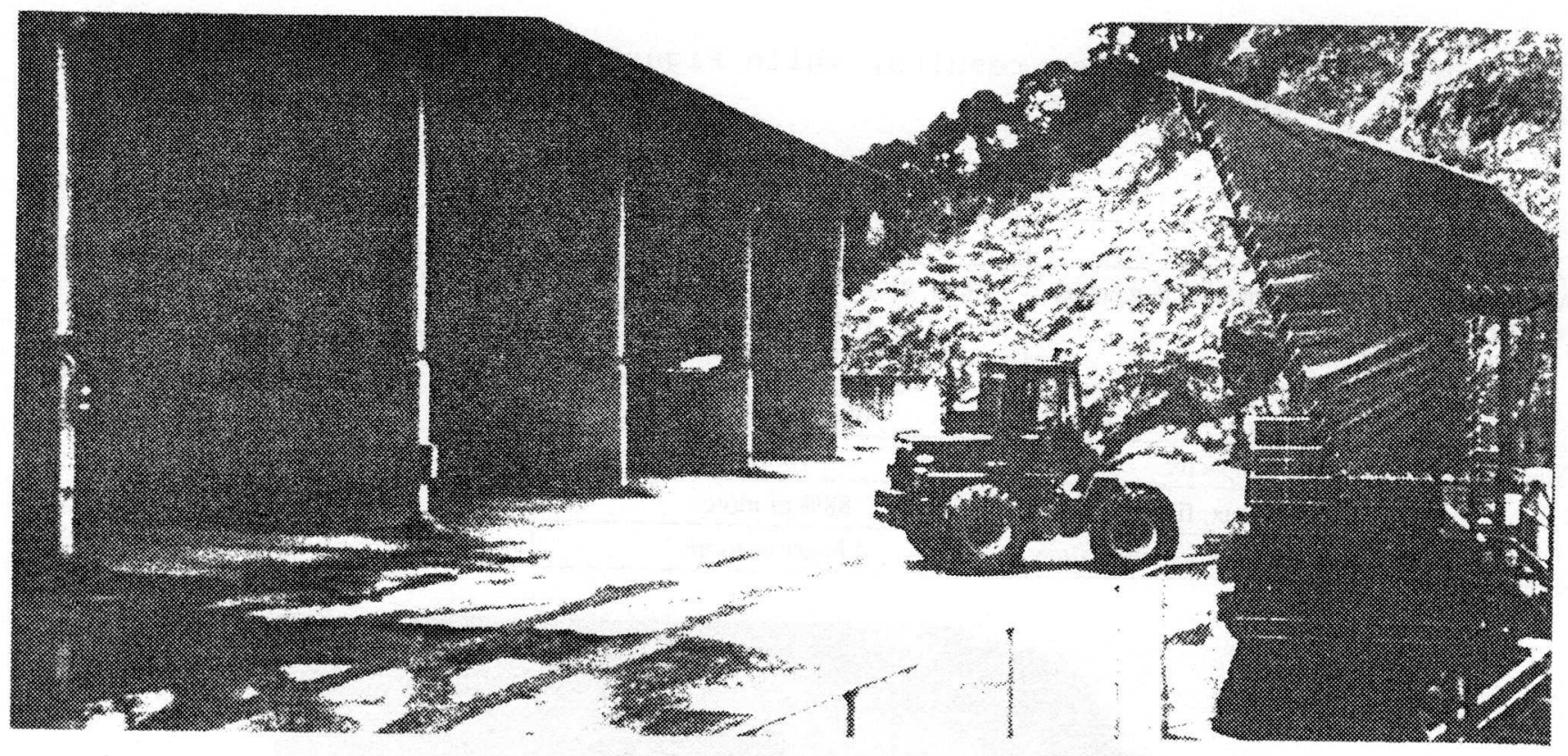

Figure 12 Test Scene

\section{CONCLUSION}

By automating the wheel loader for use in an asphalt plant, we were successful in achieving continuous automatic operation for 4 hours or more for the routine works which cover approximately $75 \%$ of the entire works to be performed by wheel loader. Thus an automatic operation system has been developed which clears the initial target of 70 ton/hour in unmanned production capacity.

We are making efforts to continue demonstration tests so that our system can be applied to other asphalt plants and are working to promote the application of other types of wheel loaders to routine works in other fields.

6. REFERENCE

(1) M. Suga et al., "Unmanned Dump-Truck System," Construction Machinery and Equipment, Vol. 23, No. 9, 1987, pp.39-4 (in Japanese)

(2) T. Nemoto, "Komatsu Automatic Guided Vehicle, "Automatic Guided Vehicle System Guidebook, Ryutsu-Kenyu Co. (1986), pp.85-109 (in Japanese) 